\title{
The Design of Notification System on Android Smartphone for Academic Announcement
}

\author{
https://doi.org/10.3991/ijim.v12i3.8494 \\ Ahmad Sanmorino $(\bowtie)$ \\ Universitas Indo Global Mandiri, Palembang, Indonesia \\ sanmorino@uigm.ac.id \\ Ricky Maulana Fajri \\ Eindhoven University of Technology, Eindhoven, Netherlands
}

\begin{abstract}
Through this article, we try to propose the design of notification system that runs on the Android operating system. This notification will be used for the academic announcements in the campus environment. The current announcement system only depends on the web portal, phones, groups in social media or short message system. The use of web portals and phones still has many limitations. Our proposed notification system can meet the needs of academic announcement broadcast quickly and massively. In the end, this will cut the cost that stakeholders need to operate the academic announcement system in the campus environment. The design of smart notification system that we proposed in the future will be integrated with the academic information system.
\end{abstract}

Keywords-notification, android smartphone, academic, announcement

\section{Introduction}

Currently, we can find notification systems on various devices, such as smartphones, smartwatch, or tablets. With the notification system, impact on the effectiveness of work that can be completed by smartphone users. In addition to providing important information, the notification also serves as a reminder of information that has occurred, is happening or will be done by the recipient. Usually, smartphone users will take the time to see or read the notification on the smartphone even in busy conditions. This is because the nature of the notification system is a fast response in conveying information to the user.

Research related to the use of notification system has been done since the birth of mobile phone device. Starting from Global System for Mobile Communications (GSM) or Code Division Multiple Access (CDMA) to Internet Protocol (IP) based, or briefly called the Internet. Examples of simple GSM-based notification systems such as voice call, short message service, and multimedia messaging service. For Internetbased notification system usually depends on the application in the operating system on a smartphone device. Android and iOS are two operating systems on the smartphone device that is quite dominate at this time. 
There have been many studies dealing with the notification system on smartphones as a solution to various problems in life [1]-[5]. Some studies that have been done include smart disaster notification system that utilizes SMS or voice call to inform optimal route to the nearest shelter [6], another example is a notification system that provides information about bus departure in detail [7]. This notification system runs on the Android operating system. Then, there is also research that uses push notification for the selection of wireless connection services, based on service and speed of access [8]. In addition to utilization, research also focuses on system performance, by testing and analysis of push notification used [9]. Through this research, we try to propose the design of smart notification system that runs on the Android operating system. This smart notification will be used for the academic announcement in the campus environment. The current announcement system only depends on the web portal, phones, groups in social media or short message system. The use of web portals and phones still has many limitations. This is the background for us to create a smart notification that runs on the Android operating system. In principle, the way the notification system work has a resemblance to the information system in common [10], which aims to provide information to users. What distinguishes it, if the information system is little passive, then the notification system is active and very dynamic. Another aspect to concern is security issues, with the use of Android-based notification system is expected to reduce theft and misuse of data. It can also open up new research opportunities, namely the integration of notification systems and server security methods as we have done in other studies [11].

\section{Research Method}

The research methodology is the steps needed to carry out the research from the beginning until the research is done. The methodology that we use in this research is as follows (Fig. 1):

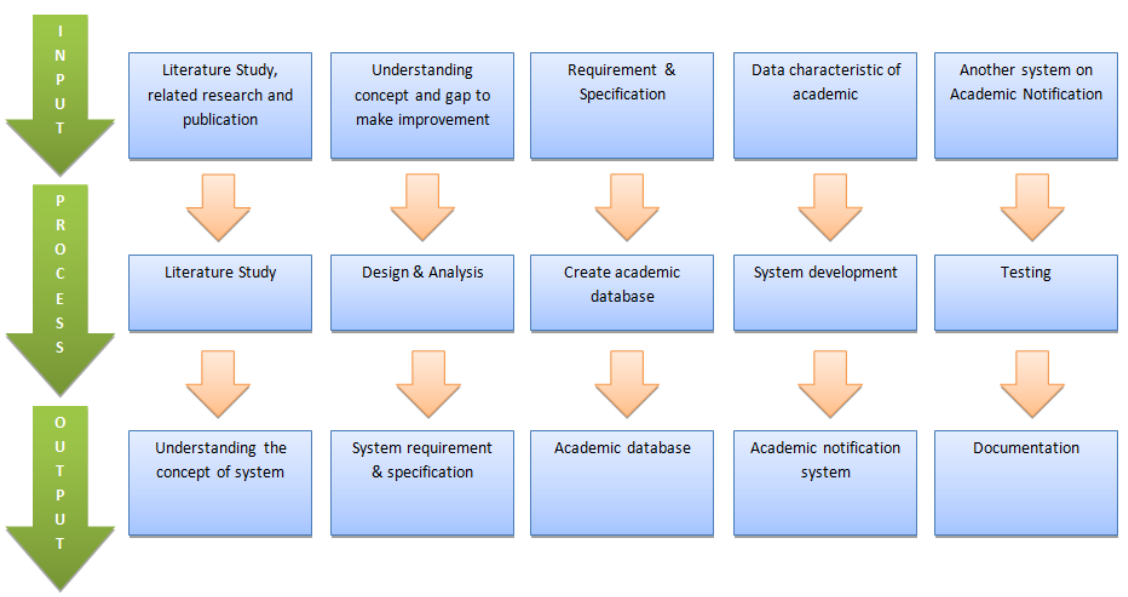

Fig. 1. The methodology to develop academic notification system 


\subsection{Literature Study and Understanding the Concept}

At this stage we do literature study, reading related research and publications that have been done by other researchers. By reading related research that has been done before, will increase the knowledge and understanding of the concept of academic notification system that will be developed.

\subsection{Make Improvement, Design and Analysis, System Requirement}

At this stage, based on the understanding that has been obtained from the previous stage, we are trying to find opportunities to improve related pre-existing research. Here we also try to fix the shortcomings and limitations in the design of notification system from previous research. Then proceed with the design to get the initial concept of notification system that will be developed. An analysis is done to determine the factors that influence the design that has been made. From the analysis results also known various shortcomings and what to add so in accordance with the requirements.

\subsection{System Development}

From the analysis results known requirement and specification of the notification system to be developed. Especially matters relating to the data and information to be stored in the database.

\subsection{Requirement and Database}

The next stage is to develop notification system based on the design, requirement and database needs that have been done in the previous stage. This stage involves designers, programmers, and analysts to communicate with each other so that the system developed to suit the needs.

\subsection{Testing and Documentation}

Further comparison of performance notification system has been developed with identical research results that have been done before. Performance comparison is done by testing the notification system. This is done to find out how well the performance of the notification system has been developed. After knowing the performance of the system, the stage is no less important is to make the documentation of the series of processes that have been done followed by documentation of notification system functions that have been developed. Because this research is still ongoing, then the progress of our research is only up to the design and analysis stage. 


\section{$3 \quad$ Results and Analysis}

The design of the notification system that we have developed into two parts namely architecture design and system design.

\subsection{Architecture Design}

For the needs of our notification services use Firebase Cloud Messaging (FCM) [12] as mobile platform service. We believe the use of FCM is very effective because, in addition to the security factor, FCM already has all the required notification features. The explanation of the features of FCM's notification feature is as follows. For most communications between clients and servers, clients will make requests to receive services from the server. In other words, the client pulls data from the server. In FCM push notification, the server is transferring data.

This can be done by maintaining a continuous TCP / IP connection and a fixed connection between the server and the client. Firebase Cloud Messaging is a service that acts as an intermediary between server and client like android smartphone users. With FCM, it can set up continuous connections for users. FCM also ensures that push notification can be done safely and reliably.

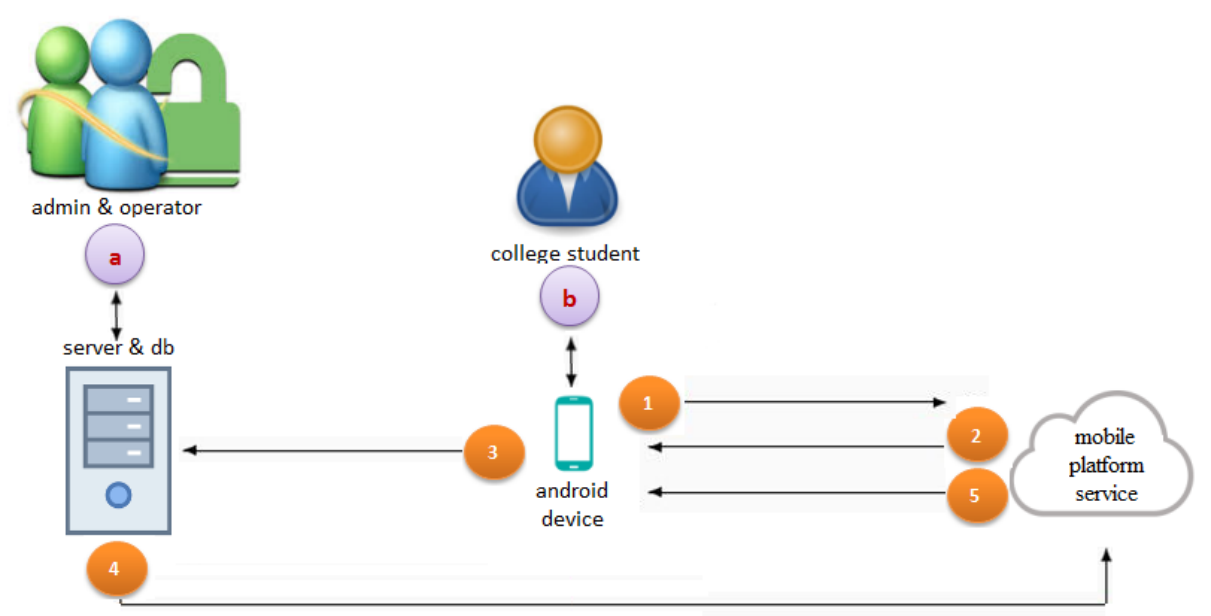

Fig. 2. The Architecture Design of Academic Notification System

In general, the academic notification system workflow (Fig. 2) is as follows:

1. Student sends ID through their Android smartphone device to mobile platform service server to register.

2. The mobile platform service will notify that the student has successfully registered, marked by a success message sent by the mobile platform service. 
3. Next, the device will send the ID that has to register with the campus server. The campus server will store the ID of the student who has done the registration into the database.

4. If there is an academic announcement, the campus server will send it to the mobile platform service.

5. Mobile platform service broadcasts to all students who have registered.

For actors involved in the system, which consists of 3 parts: admin, operator, and student.

a) Admin can manage the user, monitor the system and view the log. The operator can add or remove the student, create and view the list of announcements.

b) Students can view and read the academic notification messages sent by the mobile platform service wherever and whenever they are.

By using FCM as mobile platform service, the campus does not need to send academic announcement one by one to students such as via email, SMS, or notification technology that require a client to request to a server. The notification content provided is also more varied and interesting, not monotonous and boring. FCM also guarantees the security factor of message and notification content that is broadcast to the student who has done the registration. In other words, the failure of the notification system can be avoided. This is important to understand because if there is a failure, everything must be repeated from the beginning and will cause a lot of losses. Planning and calculation of the implementation of a system must be done correctly, to avoid failure, as we have done in other studies [13].

\subsection{System Design}

Further discussed the function of each actor involved in the notification system developed. Table 1 show functional requirements of each actor:

Table 1. The Functional requirements (FR)

\begin{tabular}{|c|l|}
\hline ID & \multicolumn{1}{|c|}{ FR } \\
\hline F-01 & Admin can manage user \\
\hline F-02 & Admin can monitor the system \\
\hline F-03 & Admin can view the log \\
\hline F-04 & Admin can manage account \\
\hline F-05 & Operator can create new announcement \\
\hline F-06 & Operator can add or revome the student \\
\hline F-07 & Operator can view the list of announcement and student \\
\hline F-08 & Operator can manage account \\
\hline F-09 & Student send an ID for registration \\
\hline F-10 & Student can see the notification \\
\hline F-11 & Student can read the academic announcement \\
\hline F-12 & Student can manage account \\
\hline
\end{tabular}


Each actor has their own interest in the notification system. Admin has full access to the notification system on campus. Admin may have multiple operators, may add or remove an operator. The operator is in charge of operating the notification system by following the rules and directives provided by the admin. In the hierarchy, students are at the lowest level, have limited access, because it can only register, see the notification and read the message academic announcement broadcast by the operator. After knowing the function of each actor involved, the following illustrates the use case diagram used in the academic notification system.

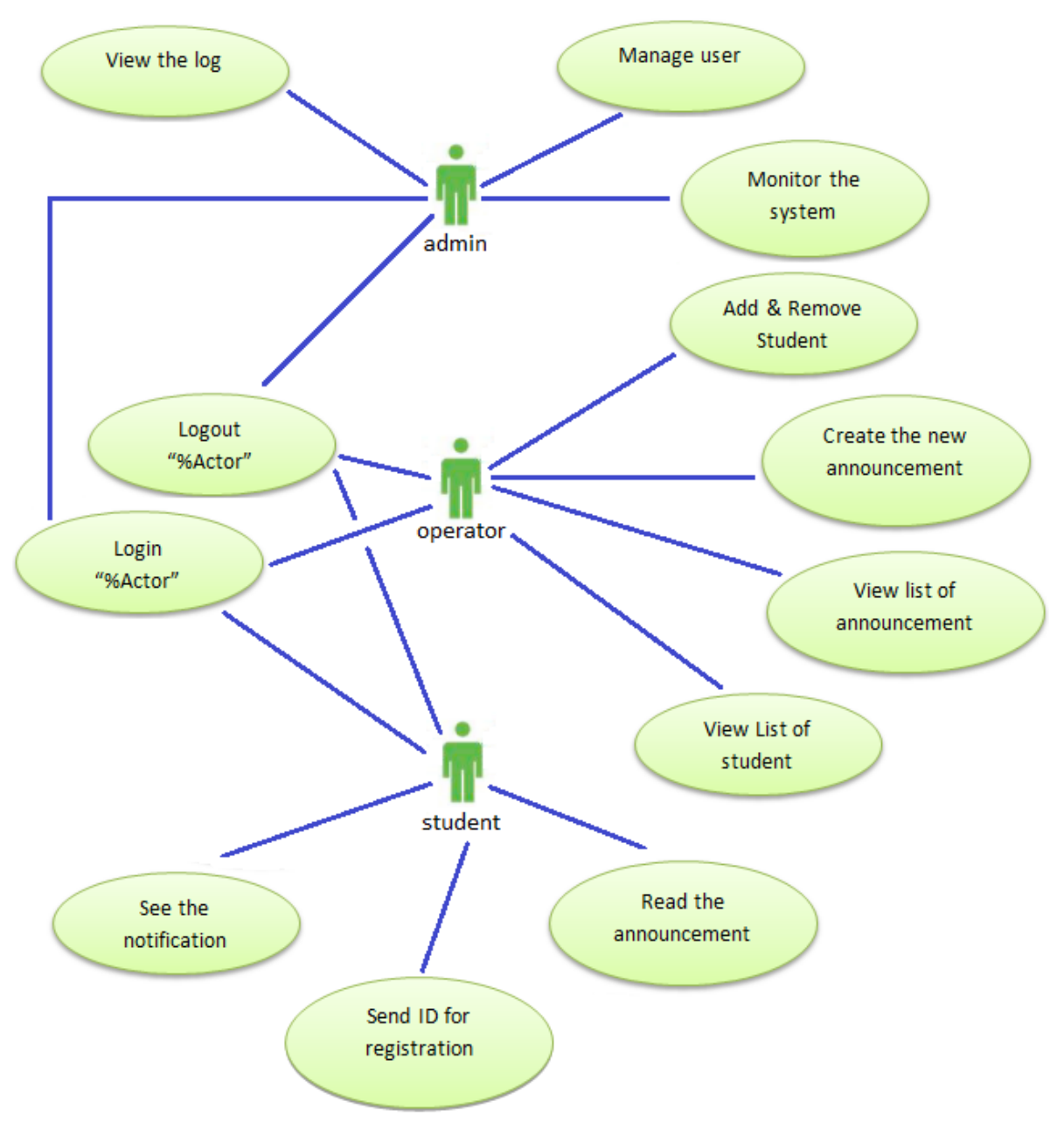

Fig. 3. The System Design of Academic Notification System

To understand the use case diagram in Fig. 3, we can see the functional requirement mapping to the use case diagram below (Table 2): 
Table 2. The Mapping beetwen Functional requirements and Use case (UC)

\begin{tabular}{|c|c|l|}
\hline FR ID & UC ID & \multicolumn{1}{|c|}{ Use Case } \\
\hline F-12 & U-01 & Login for Student \\
\hline F-09 & U-02 & Send an ID for registration \\
\hline F-10 & U-03 & See the notification \\
\hline F-11 & U-04 & Read the announcement \\
\hline F-12 & U-05 & Logout for student \\
\hline F-08 & U-06 & Login for Operator \\
\hline F-06 & U-07 & Add or Remove the student \\
\hline F-07 & U-08 & View list of student \\
\hline F-05 & U-09 & Create the new announcement \\
\hline F-07 & U-10 & View the list of announcement \\
\hline F-08 & U-11 & Logout for Operator \\
\hline F-04 & U-12 & Login for Admin \\
\hline F-01 & U-13 & Manage user \\
\hline F-03 & U-14 & View the Log \\
\hline F-02 & U-15 & Monitor the system \\
\hline F-04 & U-16 & Logout for Admin \\
\hline
\end{tabular}

By using our proposed notification system, the delivery of academic announcement can be easier to do. The time required for the broadcast process to be less and more cost-effective when compared with client-request notification system. The fundamental differences between our proposed notification system and client-request notification are as follows (Table 3):

Table 3. The Different beetwen Proposed Method (PM) and Client-request Method (CM)

\begin{tabular}{|c|l|l|}
\hline No & \multicolumn{1}{|c|}{ PM } & \multicolumn{1}{c|}{ CM } \\
\hline 1 & Auto respond & Need request from client \\
\hline 2 & Secure Insurance & Manual Setting \\
\hline 3 & Auto update & Manual Update \\
\hline 4 & Auto broadcast & One on one service \\
\hline 5 & Low time and space complexity & More time, more space \\
\hline
\end{tabular}

The use of FCM in the notification system we propose to make the business processes that occur between actors become more dynamic, with little margin of error. Another advantage is the availability of slots that can be used for academic announcement needs, enabling unregistered IDs in unlimited quantities, with the same quality of service. Opportunities to increase the number of users and get the latest features of apps, the more pampering the end users. The notification system can also be integrated with an academic information system, or can also be used as a distance learning aids. Integrated with various learning aids tools [14], that already exist in the campus environment. Finally, the opportunity to do further research is still wide open, for anyone interested in improving the performance of the current system. 


\section{Conclusion}

Our notification system can meet the needs of academic announcements broadcast quickly and massively. Without having to be burdened with the amount of fees to pay, the time and storage needed to operate the notification system. When viewed in terms of security, the proposed design notification system is also guaranteed, the latest security features are embedded in the core system used. With the increasing speed of Internet bandwidth nowadays increasingly supports the proposed system notification, which in the end more and more comfortable for the end users in obtaining services.

\section{$5 \quad$ Acknowledgment}

This work is supported by the Ministry of Research, Technology and Higher Education of the Republic of Indonesia.

\section{References}

[1] M. Ghazal, S. Ali, M. A. Halabi, N. Ali, Y. A. Khalil, "Smart mobile-based emergency management and notification system", 2016 IEEE 4th International Conference on Future Internet of Things and Cloud Workshops (FiCloudW), pp. 282-287, Aug 2016. https://doi.org/10.1109/W-FiCloud.2016.64

[2] W. Wibisono, D.N. Arifin, B.A. Pratomo, T. Ahmad, M.I. Royyana, "Fall detection and notification system using tri-axial accelerometer and gyroscope sensors of a smartphone," 2013 Conference on Technologies and Applications of Artificial Intelligence, pp. 382-385, Dec 2013. https://doi.org/10.1109/TAAI.2013.82

[3] Y. Wang, J. Wang, X. Zhang, "QTime: a queuing-time notification system based on participatory sensing data", Proc. of the 37th Annual Computer Software and Applications Conference, pp. 770-777, 2013. https://doi.org/10.1109/COMPSAC.2013.127

[4] H. Oh, L. Jalali, "Ramesh Jain, An intelligent notification system using context from realtime personal activity monitoring," Turin, Italy, 29 June-3 July 2015.

[5] A. Ronald, V. Yesmaya, M. Danaparamita, "Personal Security Tracking based on Android and Web Application,” TELKOMNIKA, Vol 16, No 2, April 2018.

[6] Md.F. Sikder, S. Halder, T. Hasan, Md. J. Uddin, M.K. Baowaly, "Smart disaster notification system," Advances in Electrical Engineering (ICAEE), 2017 4th International Conference on, Dhaka, Bangladesh, 28-30 Sept. 2017.

[7] M. Sneha, C.N. Urs, S. Chatterji, M.S. Srivatsa, K.J. Pareekshith, H.A. Kashyap, Darideepa, "A Mobile Application for bus notification system," Contemporary Computing and Informatics (IC3I), 2014 International Conference on, Mysore, India, 27-29 Nov. 2014.

[8] Z. Ji, I. Ganchev, M. O'Droma, Q Zhao, "A Push-Notification Service for Use in the UCWW," International Conference on Cyber-Enabled Distributed Computing and Knowledge Discovery (CyberC), pp. 318-322, 2014. https://doi.org/10.1109/CyberC. $\underline{2014.88}$

[9] H. Zhang, A. Rountev, "Analysis and testing of notifications in android wear applications," Proceedings of the 39th International Conference on Software Engineering, 2017. https://doi.org/10.1109/ICSE.2017.39 
[10] A. Sanmorino, Isabella, "The design a system of retention and control on broiler farms based on the flow of data," 2017 4th International Conference on Electrical Engineering, Computer Science and Informatics (EECSI), Yogyakarta, September 2017.

[11] A. Sanmorino, R. Gustriansyah, "An alternative solution to handle ddos attacks," Journal of Theoretical and Applied Information Technology, Vol. 96, No. 3, 2018.

[12] "Firebase Cloud Messaging," Google Developers, Retrieved 20 Feb 2018.

[13] A. Sanmorino, R. Gustriansyah, Terttiaavini, Isabella, "The Toolkit of Success Rate Calculation of Broiler Harvest," TELKOMNIKA, Vol. 15, No. 4, December 2017.

[14] A. Sanmorino, "Development of computer assisted instruction (CAI) for compiler model: The simulation of stack on code generation," International Conference on Green and Ubiquitous Technology (GUT), Jakarta, pp. 121-123, July 2012. https://doi.org/10.1109/ GUT.2012.6344164

\section{$7 \quad$ Authors}

Ahmad Sanmorino received the degree in Computer Science from Universitas Indonesia in 2013 and had attended a short course in Germany in 2012. Currently, he is a Lecturer at Faculty of Computer Science, Universitas Indo Global Mandiri.

Ricky Maulana Fajri received the degree in Informatics from the University of Technology Sydney in 2011. Currently, he is a Ph.D. student in the Department of Mathematics and Computer Science, Eindhoven University of Technology.

Article submitted 24 February 2018. Resubmitted 03 May 2018. Final acceptance 08 May 2018. Final version published as submitted by the authors. 